\title{
Activation of protein kinase CK2 attenuates FOXO3a functioning in a PML-dependent manner: implications in human prostate cancer
}

\author{
A Chatterjee ${ }^{1}$, U Chatterjee ${ }^{2}$ and MK Ghosh ${ }^{*, 1}$
}

Protein kinase CK2 (also known as Caseine Kinase II) is an ubiquitous Ser/Thr protein kinase present in both the nucleus and cytoplasm of cells, targeting several key enzymes, growth factor receptors, transcription factors and cytoskeletal proteins. It is not only a key player in regulating cellular growth and proliferation, but also behaves as a potent suppressor of apoptosis. CK2 has been frequently found to be deregulated (mostly hyperactivated) in all cancers, prostate cancer being prominent of them. In the recent past, tumor suppressor PML (promyelocytic leukemia) has been shown to be a target of phosphorylation by CK2. This phosphorylation promotes the ubiquitin-mediated proteasomal degradation of PML thereby effectively curbing its role as a tumor suppressor. Among many others, PML has also been established to mediate its tumor suppressive role by mitigating the inactivation of active AKT (pAKT) inside the nucleus by assembling a dephosphorylating platform for nuclear pAKT. One of the immediate consequences, of this inactivation is the stabilization of FOXO3a, another well-established tumor suppressor, inside the nucleus and its downstream activities. Here, we propose a novel signaling axis apexed by deregulated CK2, dismantling the association of PML and PHLPP2 (we also report PHLPP2 to be a novel interacting partner of PML inside the nucleus), ultimately leading to the inactivation and nuclear exclusion of FOXO3a, thereby downregulating p21/p27/Bim in which degradation of PML and the concomitant stabilization of PAKT plays a cardinal part.

Cell Death and Disease (2013) 4, e543; doi:10.1038/cddis.2013.63; published online 14 March 2013

Subject Category: Cancer

It is often an elemental feature of neoplasia that instead of major qualitative changes in the chemico-molecular make-up of the cell as a whole, the activity of one or more critical player is 'modified' from being normal. These modifications, which are invariably deregulations, may occur both at the posttranscriptional as well as at the post-translational levels., ${ }^{1,2}$ While most often, conveyance of crucial biochemical signals leading to oncogenic predisposition, occur through posttranslational modifications of the key proteins, especially in the cell nucleus. ${ }^{3-5}$ Consequently, the enzymes that bring about protein phosphorylation (most widely occurring posttranslational modification) in cell, the kinases, have thus emerged as propitious therapeutic targets in cancers. ${ }^{6}$ Protein kinase CK2 is a profoundly conserved, perpetually expressed, messenger independent and constitutively (presumably) active serine or threonine kinase that can use ATP as well as GTP as co-substrate localized in cell nucleus and cytoplasm. ${ }^{7,8}$ In the past decades, numerous evidences have mounted in support of the importance of CK2 in diverse biological processes, particularly emphasizing its function in controlling cellular growth and proliferation in both normal and diseased contexts. ${ }^{9}$ CK2 has been established as a potent suppressor of apoptosis especially in the context of neoplasia, since it has been found to be frequently heightened in most of the cancer systems and thus has become a generalized signature of oncogenesis. ${ }^{10-12}$ One of the significant aspects of CK2-mediated alternation of normal cellular physiology is the nuclear role of $\mathrm{CK} 2$, which has been strongly implicated in most cancers. Among its nuclear substrates, are so-called non-histone phospho-protein component of the nucleus is now known to be a mixture of a wide variety of proteins encompassing structural proteins, transcription factors, various enzymes, receptor proteins, and most importantly some crucial tumor suppressors and regulators of apoptosis. ${ }^{11,13-16}$ One such critical controller which is targeted for functional disruption by CK2 is the promyelocytic leukemia $(P M L)$, protein which is an essential tumor suppressor in cell. ${ }^{17} \mathrm{CK} 2$ regulates $\mathrm{PML}$ protein levels by directly phosphorylating it

\footnotetext{
${ }^{1}$ Division of Cancer Biology and Inflammatory Disorder, CSIR-Indian Institute of Chemical Biology, 4, Raja S.C. Mullick Road, Kolkata 700032, India and ${ }^{2}$ Division of Pathology, Park Clinic, 4, Gorky Terrace, Kolkata 700017, India

${ }^{*}$ Corresponding author: MK Ghosh, Cancer Biology and Inflammatory Disorder Division, Indian Institute of Chemical Biology, Council of Scientific and Industrial Research (CSIR), 4, Raja S.C. Mullick Road, Jadavpur, Kolkata, West Bengal 700032, India. Tel: +9133 24995889 ; Fax: +91 33 2473 0284/5197; E-mail: mrinal.res@gmail.com

Keywords: CK2; PML; FOXO3a

Abbreviations: CK2, caseine kinase 2; PML, promyelocytic leukemia; FOXO3a, forkhead box O3 isoform a; PHLPP2, PH domain and leucine-rich repeat protein phosphatase 2; PCa, human prostatic carcinoma/prostate cancer; PHp, human prostatic hyperplasia/prostate hyperplasia; TBCA, (E)-3-(2,3,4,5-Tetrabromophenyl) acrylic acid; CHX, cycloheximide; qRT-PCR, quantitative real-time polymerase chain reaction; WCL, whole-cell lysate; CE/NE, cytoplasmic extract/nuclear extract; SDSPAGE, sodium dodecyl sulfate-polyacrylamide gel electrophoresis; IP, immunoprecipitation; IB, immunoblot; FACS, fluorescence-activated cell sorting; RT, room temperature; PBS, phosphate-buffered saline; TBS-T, Tris-buffered saline with Tween-20; Indv, individual; NBs, nuclear bodies; Coeff, coefficient; OI, oil immersion Received 27.11.12; revised 28.1.13; accepted 04.2.13; Edited by G Ciliberto
} 
(at residue Ser517) and promoting for ubiquitin-mediated degradation. ${ }^{18,19} \mathrm{PML}$ is the essential component of PML-nuclear bodies (PML-NBs), functioning as the organizing center of this structure and acting as a multifaceted scaffold for various cellular proteins. PML-NBs are known to modulate various cellular activities, most of them being related to oncogenesis. ${ }^{20,21}$ Of many such proteins, AKT is a potent pro-oncogenic kinase, whose aberrant nuclear functioning is precisely supervised by PML-NBs under normal circumstances, by orchestrating active AKT (phosphorylated form) and its phosphatases, whereby AKT is dephosphorylated, hence inactivated. ${ }^{22}$ This inactivation, coupled with nuclear expulsion of AKT, has a considerable effect on rightful functioning of many tumor suppressor proteins, FOXO3a being eminent among them, which is otherwise phosphorylated (at multiple Serine, Threonine residues) and deactivated by active nuclear AKT (the ultimate fate of the phosphorylated FOXO3a is proteasomal degradation, following nuclear expulsion). ${ }^{23-26}$ The end point manifestation of the above-mentioned signaling dynamics is the repressed activity of $\mathrm{FOXO} 3 a$ implicated significantly by uncontrolled cellular proliferation coupled with reduced apoptosis.

Here, in the present study we demonstrate that a finely orchestrated signaling concatenation operates, commanded by $\mathrm{CK} 2$, causing untimely degradation of $\mathrm{PML}$ thereby perpetuating abnormal activity of AKT inside the cell nucleus. Inhibition of CK2 activity reverses the above-described signaling dynamics manifested by lowered cellular proliferation and apoptosis. Moreover, for the first time (to the best of our knowledge) we also report that PHLPP2, another well-established canonical phosphatase of $\mathrm{AKT}^{27,28}$ interacts with PML in the NBs, effecting dephosphorylation of AKT, thus rendering it inactive which ensures proper functioning of FOXO3a.

\section{Results}

Inhibition of CK2 activity significantly affects morphology and migrational ability of prostate cancer cells. CK2 has been described as a multifunctional protein kinase having vital roles in cellular functioning of both normal and cancerous cells, including survival, proliferation and metastasis. ${ }^{29,30}$ CK2 is abnormally deregulated in all human malignancies that have been examined till date, especially prostate cancer $(\mathrm{PCa}),{ }^{31}$ where CK2 plays an essential role in maintaining oncogenesis and related prognosis. The comprehensive effect of inhibition of CK2 on PC3 cells were established by inhibiting CK2 and observing the effects on cellular morphology (Figure 1a). We observed that cells significantly lost their normal morphology following inhibition of CK2. Cells lost their conventional elongated architecture and assumed a spherical, rounded-up appearance, evident of considerable depletion of vital survival and sustenance signaling that was otherwise provided by CK2. The importance of CK2 is even more highlighted by the fact that a comparable effect was achieved by inhibiting AKT signaling, another well-established essential survival factor. ${ }^{32}$ On exploring the effect of CK2 inhibition on cancer cell migration (Figure 1b), we encountered that even a low but enduring inhibition of CK2 signaling noticeably hampers the characteristic, normal migrational movement of PC3 cells. Here also, the detrimental effect of CK2 inhibition is even profound than that of inhibition of PI3K/AKT signaling, which reinforces the fact that CK2 is not only an essential homeostatic kinase for cell, but also an indispensible 'onco-kinase' for cancers.

Activation of CK2 promotes decline of PML level in PCa cells. In our present study, we are more concerned with pro-oncogenic effect of CK2 in the cell nucleus hence, tumor suppressor PML becomes an appropriate target for

a

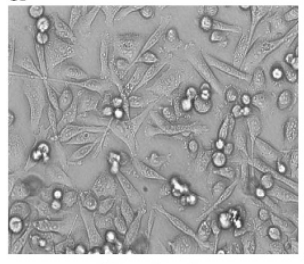

Control

b

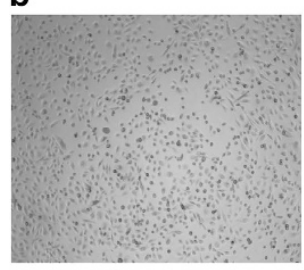

Control

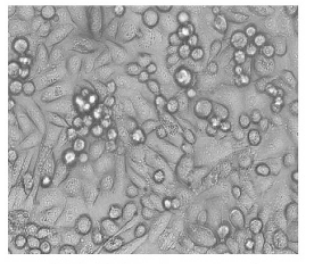

DMSO treated

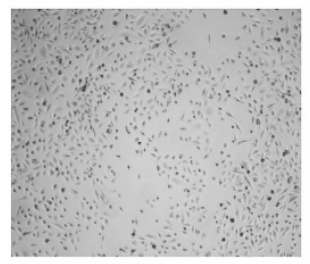

DMSO treated

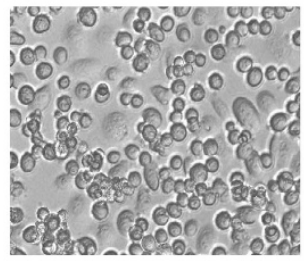

10uM TBCA

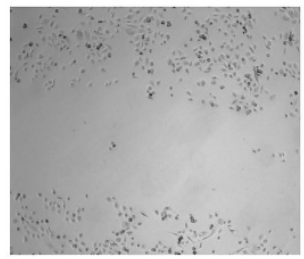

5UM TBCA

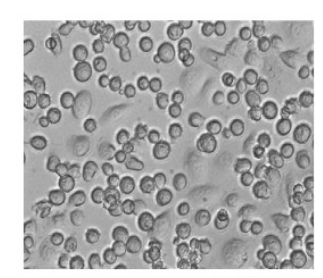

25uM LY249002

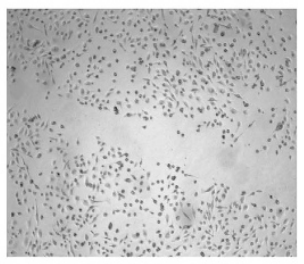

5uM LY249002

Figure 1 Inhibition of CK2 activity significantly affects cellular morphology and migrational ability. (a) Human prostate cancer cells, PC3 were treated with TBCA at the indicated dose for $4.0 \mathrm{~h}$. LY249002 treatment at the indicated dose was used as a positive control, duration being same. All images were taken at $\times 200$ magnification using inverted microscope. Cells treated with DMSO served as experimental control. (b) In vitro Scratch Assay, to delineate the effect of CK2 inhibition upon cell migration. TBCA was added along with fresh medium at the indicated concentrations. LY249002 treatment was used as positive control while cells treated with DMSO served as experimental control 
investigation. $^{19}$ Here, we depict that $\mathrm{CK} 2$ elicits PML degradation in PC3 cells, as evident from the apparent contrast in the number of PML-NBs, in the conditions where the activity of CK2 is either enhanced or inhibited (Figure 2a). The experiment was performed for multiple times to quantify the absolute number of PML-NBs with the required statistical significance and the average quantification of PML-NBs, depicting significant variance under the differential condition of CK2 activation and inhibition is represented (Figure 2b). Values clearly depict that CK2 is acutely responsible for PML degradation, and upon its inhibition, PML is noticeably stabilized. Microscopy results were corroborated by inspecting the change in $\mathrm{PML}$ protein level by conventional immunoblot analyses under the above-mentioned conditions of CK2 activation and inhibition (Figure 2c). Results are appreciably demonstrating of the fact that $\mathrm{PML}$ is stabilized under the situation of CK2 inhibition. In order to demonstrate the time-dependent degradation of PML upon over-activation of $\mathrm{CK} 2$, the level of PML protein was evaluated at increasing duration of CK2 activation. PML is observed to exhibit a gradual loss of protein level over time, most prominent at $1 \mathrm{~h}$ after the treatment (Figure 2d). A contrasting pattern of gradual stabilization of PML protein level was achieved upon increasing duration of CK2 inhibition (Figure 2e; Supplementary Information S-3a), but the increase was not statistically significant enough (Supplementary Figure S-3b). To validate the fact that indeed CK2 drives PML towards proteasomal degradation, the approach of blockade of the proteasomal system was adapted with simultaneous overexpression of CK2 (Figure 2f), in case PML is degraded via proteasomal system, then, occluding it will prevent the loss of PML protein level, comparable with that of CK2 inhibition.

Tumor suppressor PML interacts with phosphatase PHLPP2 in the nucleus. As it has been established that PML-NBs orchestrates a broad spectrum docking scaffold for a multitude of nuclear proteins in order to regulate their activity and AKT is prominent of them, ${ }^{22}$ we felt interested to

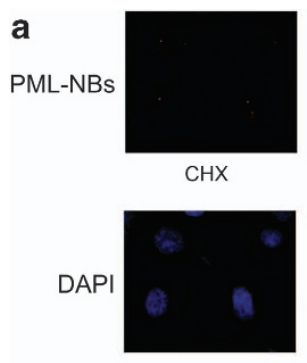

$\mathrm{CHX}$

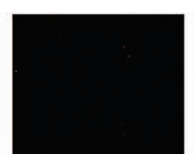

$\mathrm{CHX}+$ Sorbitol(S)

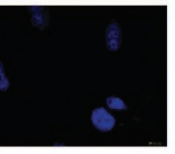

$\mathrm{CHX}+$ Sorbitol(S)

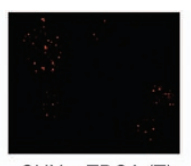

$\mathrm{CHX}+\mathrm{TBCA}(\mathrm{T})$

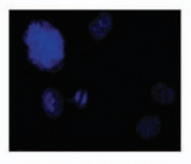

$\mathrm{CHX}+\mathrm{TBCA}(\mathrm{T})$
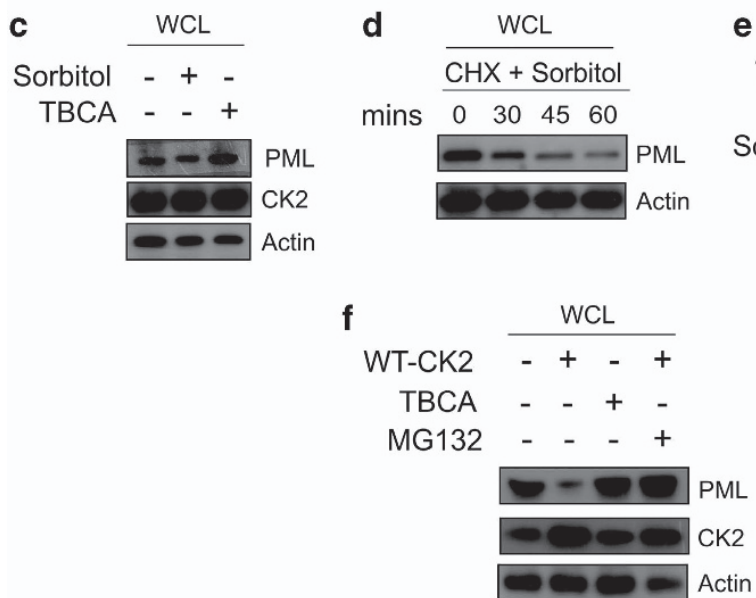

e

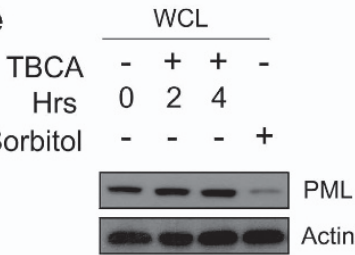

b

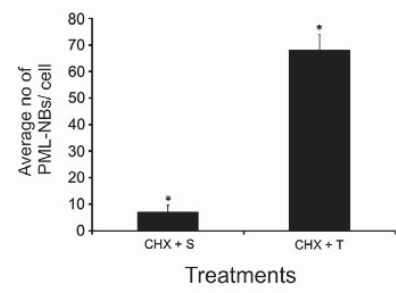

Actin

Figure 2 Activation of CK2 reduces number of PML-NBs. (a) Immuno-fluorescence detection of PML-NBs: PC3 cells were treated with $d-$ Sorbitol and TBCA (prior harvesting) simultaneously with $\mathrm{CHX}$. Cells were processed appropriately for immuno-fluorescence imaging and were observed under microscope. (b) Quantification of average number of PML-NBs. PC3 cells being treated with either $d-$ Sorbitol or TBCA in combination with CHX. PML-NBs were counted from 480 cells (nuclei) out of 80 randomly chosen fields (16 fields from each experiment; number of biologically repeated experiments being five). Bars represent mean ( \pm ) S.D. of the five independent biological repeats with the ${ }^{*} P=0.031$ level of significance. (c) Level of PML protein is increased upon inhibition of CK2 activity. PC3 cells were treated either with $d-$ Sorbitol or TBCA and lysates were separated on SDS-PAGE and probed with mentioned antibodies. (d) Activation of CK2 decreases PML protein stability. PC3 cells were treated with $d-$ Sorbitol along with CHX. Cells were harvested, and lysates were subjected to IB and probed with the indicated antibodies. (e) PML protein level increases with increasing duration of CK2 inhibition. PC3 cells were treated either with TBCA or with $d-$ Sorbitol. Lysates prepared from the treated cells were immunoblotted with anti-PML antibody. (f) Exogenously overexpressed CK2 decreases PML protein level by promoting proteasomal degradation. PC3 cells were transfected with either wild-type (WT) CK2 $\alpha$ alone or followed by MG132 treatment (after $32 \mathrm{~h}$ of post-transfection). Lysates were prepared and subjected to IB analyses with respective antibodies as mentioned. Cells treated with TBCA served as positive control. Control cells had appropriate empty vector transfection along with DMSO treatment at the required quantity. In all the cases, bars represent $( \pm$ ) S.D. of three independent biological repeats at the mentioned level of significances. Cells treated with DMSO-water (in a, $\mathbf{c}, \mathbf{d}$ ) or water only (in e) were used as respective controls 
look for whether alike PP2a, ${ }^{22}$ PML could interact with another well-established phosphatase of AKT, viz. PHLPP2, which dephosphorylates AKT at the Ser473 residue ${ }^{27}$ to bring about inactivation of AKT in the nucleus itself. Indeed, we found PHLPP2 to be interacting with endogenous PML, and the amount of co-interacted protein decreases with the decrease in the level of PML, which is obviously due to CK2mediated degradation (Figure 3a). On the other hand, the level of interacting PHLPP2 depicted increment with stabilization of PML, brought about by inhibition of CK2 activity (Figure 3b). Similar phenomenon is observed through quantification of co-localization coefficient through time-lapse microscopy (Figure 3c), where PHLPP2 depicts a measurable increase in co-localization with PML when CK2 is inhibited compared with untreated cells. We have also quantified the change in the level of co-localization, which manifests a distinct progressive increase with increased duration of CK2 inhibition (Figure 3di). When the coefficient of co-localization for PAKT-PML was determined, it illustrated an opposite depiction, where the coefficient value for colocalization decreased uniformly with increasing duration of inhibition of CK2 activity (Figure 3dii). The initial rise in the co-localization level (at 15 min of TBCA treatment) is justified by the fact that $\mathrm{PML}$ itself undergo certain degree of stabilization owing to CK2 inhibition, even at that brief exposure to TBCA, but with increasing time and with simultaneous stabilization of PML, the level of nuclear pAKT drops, again supporting our hypothesis that PML-PHLPP2 association successfully diminishes nuclear $\mathrm{AKT}$, and the reduction in the level of nuclear PAKT is faithfully reflected by the reduction of the PML-pAKT colocalization coefficient. Fluorescent immunohistochemical analysis of $\mathrm{PCa}$ tissue samples reveal a noticeable level of endogenous co-localization between PHLPP2 and $\mathrm{PML}$ (Figure $3 \mathrm{e}$ ) reinforcing our findings in vivo.

The level transcriptionally inactive form of FOXO3a (pFOXO3a-S253) declines with concurrent reduction of active AKT (pAKT-S473) in the nucleus following the CK2-(PML-PHLPP2) signaling axis. Pursuing our hypothesis, we next investigated, whether the PHLPP2 was indeed effective to dephosphorylate, hence deactivate AKT

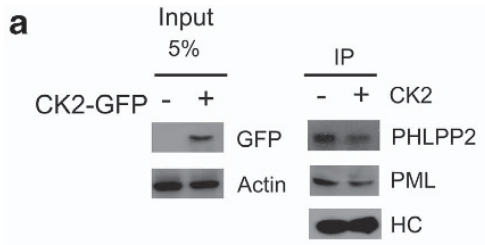

c PML \& PHLPP2 Colocalization

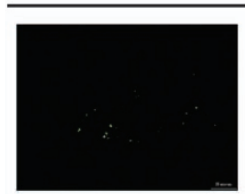

Control

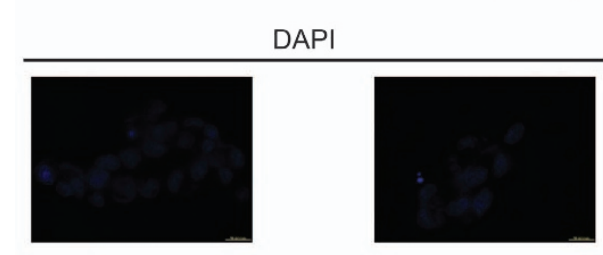

Control

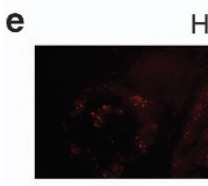

PML

Human PCa tissue
TBCA (2.0 hr)

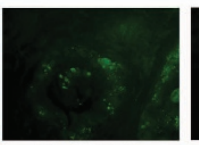

PHLPP2

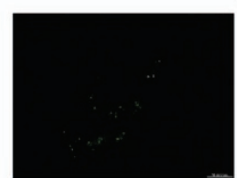

TBCA $(2.0 \mathrm{hr})$

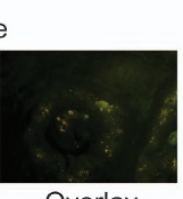

Fluorescence-IHC
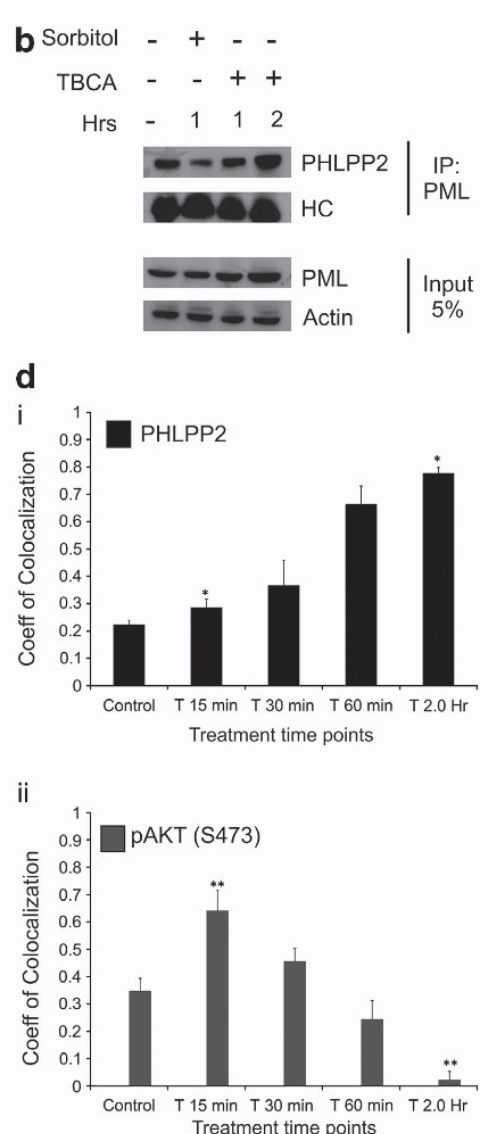

Figure 3 Tumor suppressor PML interacts with phosphatase PHLPP2 in the nucleus. (a) Interaction between PML and PHLPP2 in PC3 cells decreases with CK2 overexpression. PC3 cells were transfected with WT-CK2 $\alpha$. Lysates were subjected to IP with anti-PML antibody ( ${ }^{*} P G-M 3 ;$ mouse monoclonal) followed by IB with PHLPP2 antibodies. (b) Interaction of PHLPP2 with PML varies with PML level in the cell. PC3 cells were treated with either $d$-Sorbitol or TBCA for the indicated time points. IP was performed from the lysates, with anti-PML antibody followed by IB with PHLPP2 antibody. Control cells were treated with DMSO-water. (c) Endogenous co-localization of PHLPP2 and PML increases with CK2 inhibition/PML stabilization. (d) (i-ii) Quantitative depiction of correlation coefficient through time-lapse co-localization with increasing duration of TBCA treatment. PC3 cells were treated with TBCA and processed for in vitro time-lapse co-localization by simultaneously probing with either anti-PML and antiPHLPP2 antibody or anti-PML and anti-pAKT(S473) antibody in combinations. Pearson's Coefficient of co-localization was determined at the indicated time points and quantitatively plotted. The level of significance $\left({ }^{\star} P=0.022\right.$ and $\left.{ }^{*} P=0.017\right)$, respectively. (e) Representative figure depicting $\mathrm{Co}-\mathrm{localization}$ of $\mathrm{PML}$ and $\mathrm{PHLPP} 2$ in $\mathrm{PCa}$ tissues. In every case, bars represent $( \pm)$ S.D. of three independent biological repeats at the mentioned level of significances 
inside the nucleus. Analysis of pAKT level in the separate cytoplasmic and nuclear fractions demonstrated that upon sufficient knockdown of both PML and PHLPP2 (Figure 4ai), active AKT gets significantly stabilized in the nuclear pool in comparison to the cytoplasm (Figure 4aii). Similar observation is achieved after fluorescent microscopy analysis of PC3 cells, this time activating and inhibiting CK2 (Supplementary Figure S-4a). It is clearly evident that upon inhibition of CK2 activity, the nuclear pool of active AKT diminishes noticeably, in contrast to when CK2 activity was enhanced. LY294002 treatment serves as the established control for PI3K/AKT inhibition. Since CK2 exert considerable effect on AKT activation by phosphorylation of Ser129 residue of $\mathrm{AKT}^{33}$ (Supplementary Figure S-4b, upper figure), the CK2 refractory mutant was prepared (non-responsive towards perturbation in the level of CK2 activity) viz. AKT-S129D, in which the putative phosphorylation site of CK2 has been rendered constitutive phospho-mimetic, hence this mutant form of AKT

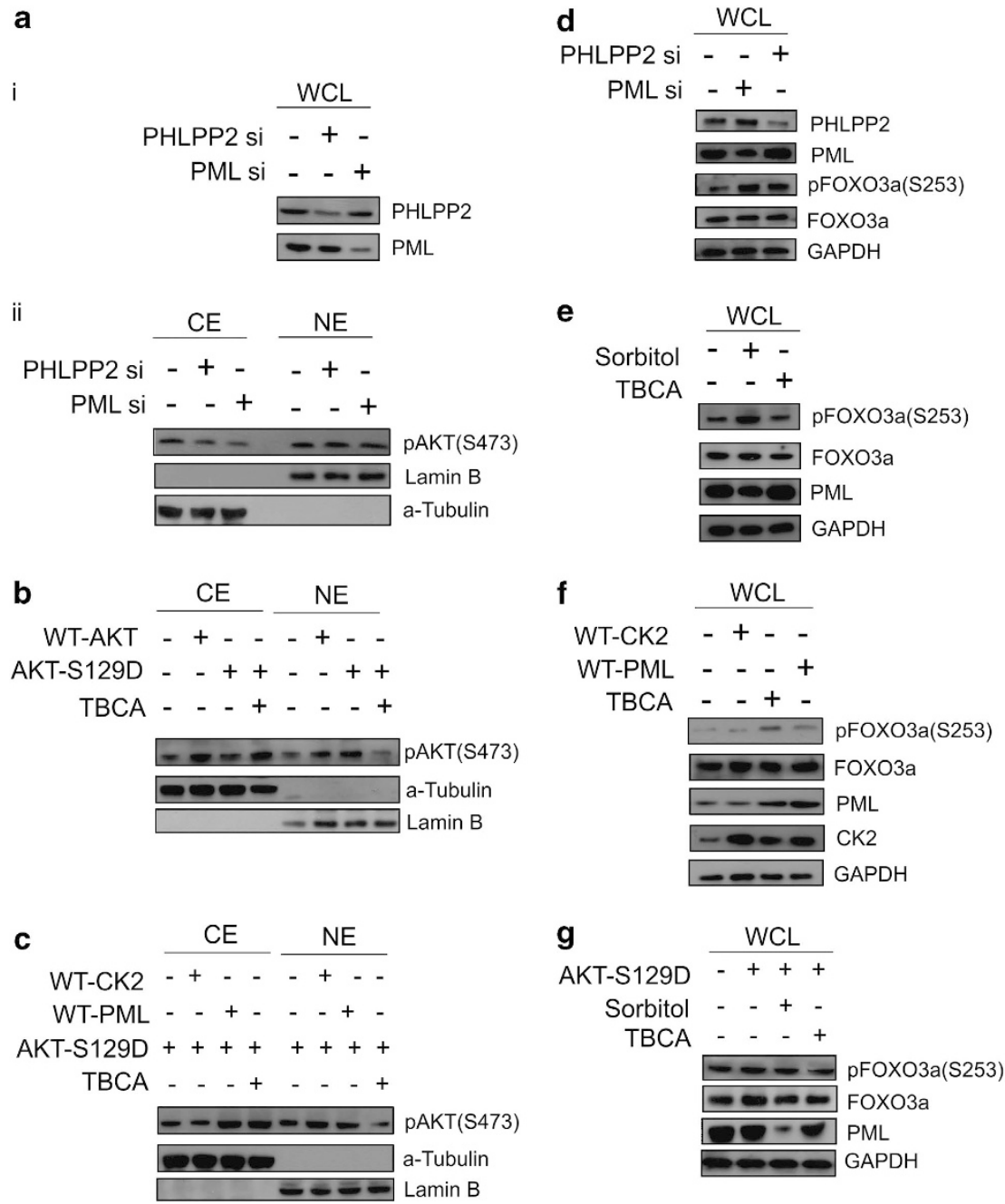

Figure 4 The pattern and intensity of protein expression of both activated AKT (pAKTS473) and pFOXO3a(S253) follows the PML-PHLPP2 signaling axis, which is governed by the activity status of CK2. (a) (ii) Both knockdown of PML and PHLPP2 (i) maintains a higher nuclear level of pAKTS473. PC3 cells were transfected with either scrambled si RNA (Control) or PML si or PHLPP2 si. Cells were harvested and fractionated into CE and NE. The lysates were separated on SDS-PAGE, followed by IB with anti-pAKTS473 antibody. (b) AKT-S129D is enhanced in the nucleus under normal condition, while it is significantly depleted from NE fraction upon inhibition of CK2 activity. HEK293 cells were transfected with either WT-AKT or AKT-S129D vectors or the latter also being treated with TBCA. Cells were harvested and fractionated into CE and NE. The lysates were subjected to IB analysis with anti-pAKTS473 antibody. (c) The level of AKT-S129D is lowered in the nucleus by exogenously overexpressed PML. HEK293 cells were transfected with AKT-S129D. Same cells were either transfected with WT-CK2 $\alpha$ or WT-PML or treated with TBCA. CE and NE fractions were prepared and subjected to IB analysis with anti-pAKTS473 antibody. Cells treated with TBCA served as positive control. (d) Both knockdown of PML and PHLPP2 results into heightened level of pFOXO3a. PC3 cells were transfected with either scrambled si RNA or PML si or PHLPP2 si. Lysates were prepared from cells, harvested after $72 \mathrm{~h}$ of posttransfection and subjected to IB analysis, being probed with the indicated antibodies. (e) Activation of CK2 similarly results into increase in the level of pFOXO3a, while inhibition of CK2 produces the antagonistic effect. PC3 cells were treated with either $d-$ Sorbitol or TBCA. Lysates were obtained after indicated duration of time and analyzed through IB by probing with mentioned antibodies. (f) Exogenous overexpression of WT-CK2 $\alpha$ and WT-PML has antagonistic effect on the level of pFOXO3a. PC3 cells were transfected with either WT-CK2 $\alpha$ or WT-PML and lysates were prepared and separated on SDS-PAGE followed by IB with the indicated antibodies. (g) AKT-S129D increases FOXO3a phosphorylation at Ser253 residue, while reversal of the phenomenon occurs with simultaneous inhibition of CK2. PC3 cells were transfected with AKT-S129D and also simultaneously treated with either $d$-Sorbitol or TBCA. Lysates were immunoblotted with the indicated antibodies. Control cells (in b, c, e) were treated with empty vector along with appropriate amount of DMSO-water 
appears to be insensitive towards changes in CK2 activity, as evident from the protein-level analysis of pAKT upon both enhancement and inhibition of CK2 activity (Supplementary Figure S-4b, lower figure). Under normal situation, the localization pattern of AKT-S129D is chiefly nuclear, owing to its constitutive activity due to phospho mimicking, but upon inhibition of CK2 activity, the nuclear level of active AKT declines significantly (Figure 4b), while increases in the cytoplasmic fraction, as it happens when PML is overexpressed (Figure 4c). All the findings collectively support the existence of a finely orchestrated signaling circuitry commanded by CK2, with PML and PHLPP2 as nodal players, engaged in the deactivation of nuclear AKT. On assessing the level of phosphorylated FOXO3a pFOXO3a, the inactivated form, ${ }^{34}$ upon knocking down $P M L$ and PHLPP2 expression, we observed that the amount of pFOXO3a consequentially elevates (Figure 4d), supposedly due to the loss of the control (here negative) over active nuclear AKT by PML-PHLPP2. The pFOXO3a level is distinctively reduced, both upon inhibition of CK2 activity (Figure 4e) and overexpression of exogenous PML (Figure 4f), while an absolute opposing depiction is obtained upon enhancing CK2 activity (Figure 4e), affirmed by exogenous expression of CK2 (Figure 4f), where in both the scenario, the amplitude of pFOXO3a is significantly heightened. Immuno-fluorescence imaging of PC3 cells reveals the fact that $\mathrm{pFOXO3a}$ level in the nucleus, diminishes noticeably upon inhibition of CK2 activity (the arrow mark), which is otherwise markedly nuclear under CK2 over-activation (Supplementary Figure S-4c). Upon exogenous overexpression of AKT-S129D, the level of pFOXO3a is increased, which appears to diminish when CK2 is being inhibited simultaneously (Figure $4 \mathrm{~g}$ ). All the aforesaid observations establish that CK2 is significantly responsible for AKT-mediated inactivation of FOXO3a, and its subsequent nuclear expulsion through a revoked PML-PHLPP2 association.

\section{Protein kinase CK2 negatively regulates transcriptional} activity of FOXO3a following the (PML_PHLPP2)PAKT-FOXO3a signaling axis. FOXO3a is a transcription factors having crucial tumor suppressive roles. ${ }^{35}$ The inactivation, coupled with nuclear expulsion of FOXO3a will certainly affect its downstream genes. p2 $7^{\text {Kip } 1}$ is among the signature genes, whose expression is governed chiefly by FOXO3a. Analysis of $\mathrm{p} 27^{\mathrm{Kip} 1}$ and Bim mRNA expression revealed that the transcriptional expression of both these genes are increased upon both PML overexpression, and CK2 inhibition, while gets repressed by CK2, and AKTS129D overexpressions (Figure 5a). Analogous results are obtained, when TM-FOXO3a is overexpressed along with inhibition of CK2 activity (Figure 5b) at different duration of time, where mRNA expression is further amplified due to inhibition of CK2 activity. An interesting result was achieved when the gene expression of $\mathrm{p} 27^{\text {Kip1 }}$ and Bim were quantified upon AKT inhibition alone and followed by CK2 inhibition. The expected rises in the mRNA level of both the genes were further amplified due to CK2 inhibition (Supplementary Figure S5-b). Further, to verify this observation, luciferase reporter assay of p2 $7^{\text {Kip } 1}$ promoter was carried out. It is clearly evident, both CK2 and AKT-S129D downregulates the promoter transactivation, while the promoter activity was notably enhanced upon inhibition of CK2 and overexpression of PML (Figure 5c). Noticeably simultaneous inhibition of CK2 along with overexpression of FOXO3a further augments promoter firing, while, CK2 inhibition successfully rolls back the inhibiting effect of AKT-S129D too. Similar observation is made with reporter assay with p21 ${ }^{\text {Cip1 }}$ (another FOXO3a controlled gene ${ }^{36}$ ) gene promoter also (Supplementary Figure S-5a). The observation at the transcription level was faithfully imitated at the protein level, where both enhancement of CK2 activity and CK2 overexpression reduced the protein expression of $\mathrm{p} 27^{\text {Kip1 }}$ and Bim, while the protein levels were intensified upon CK2 inhibition and PML overexpression, respectively (Figures $5 e$ and f). If the increase or decrease in the FOXO3a targets was really due to the (PML-PHLPP2)-pAKT signaling axis, then reduction in the protein levels of $P M L$ and PHLPP2 must affect the transcription and translation of p2 $7^{\text {Kip } 1}$ and Bim in a negative way. Indeed, upon knockdown of either PML or PHLPP2, both the mRNA and protein expression of the two genes gets significantly inhibited (Figures $5 d$ and $g$ ). VEGF, a gene whose expression is negatively controlled by $\mathrm{FOXO}^{3} \mathrm{a}^{37}$ exhibits an opposite pattern of both mRNA and protein expression in comparison to $\mathrm{p} 27^{\text {Kip } 1}$ and Bim (Figure 5h; Supplementary Information $\mathrm{S}-5 \mathrm{c}$ and $\mathrm{d}$ ). The involvement of nuclear AKT is further reinforced, by the observation that the expression of $p 27^{\text {Kip1, }}$ Bim and VEGF is hampered upon AKT-S129D overexpression, which is successfully regained by inhibiting CK2 (Supplementary Figure S-5e). All the results collectively indicate that the [CK2-(PML-PHLPP2)-pAKT-FOXO3a] signaling axis is functional even up to the gene expression level, and significantly regulates the expression pattern of crucial FOXO3a targets.

Inhibition of protein kinase CK2 significantly arrests cell proliferation followed by apoptosis in cancer cells. Our previous observations have demonstrated that inhibition of CK2 stabilizes active FOXO3a in the nucleus, which consequently upregulates p27 Kip1 and Bim (also p21 Cip1). Among these, $\mathrm{p} 27^{\text {Kip1 }}$ is well established as a tumor suppressor being a crucial controller of cellular proliferation, also in $\mathrm{PCa},{ }^{38}$ hence its significant augmentation along with $\mathrm{Bim}$, another pivotal factor influencing apoptosis ${ }^{39}$ is reflected in the analysis of cell cycle. Inhibition of CK2 significantly perturbs cell-cycle progression which is evident from the increase of percentage of cells in the sub- $G_{0} / G_{1}$ and $G_{0} / G_{1}$ phases of cell cycle. On the other hand, exogenous overexpression of CK2, drives the cell back into the proliferative state (Figures $6 a$ and $b$ ). The higher dose of CK2 inhibition even causes substantial amount of cell death, as revealed from the distinct increase in sub- $\mathrm{G}_{0} / \mathrm{G}_{1}$ cell population. An antagonistic scenario among cells with empowered CK2 activity and with CK2 activity being inhibited is evident from the cumulative quantification of cell percentage at sub- $G_{0} / G_{1}$ and $G_{0} / G_{1}$ phases of cell cycle (Figure $6 c$ ). The increase in the level of apoptosis upon inhibition of CK2 activity is agreeably comparable with cells treated with Camptothecin as depicted by Annexin-V staining (Figures $6 \mathrm{~d}$ and e). 


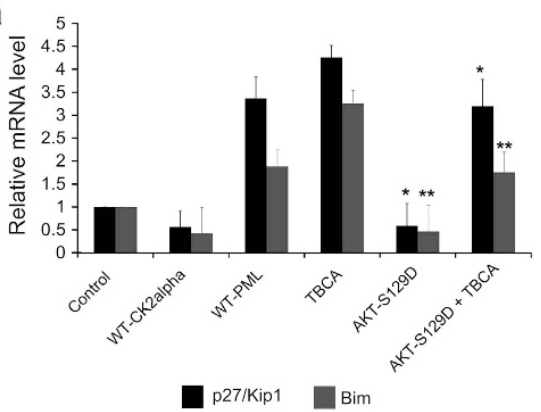

C

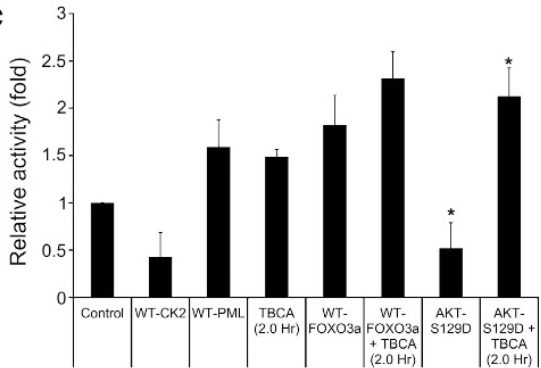

p27/Kip1
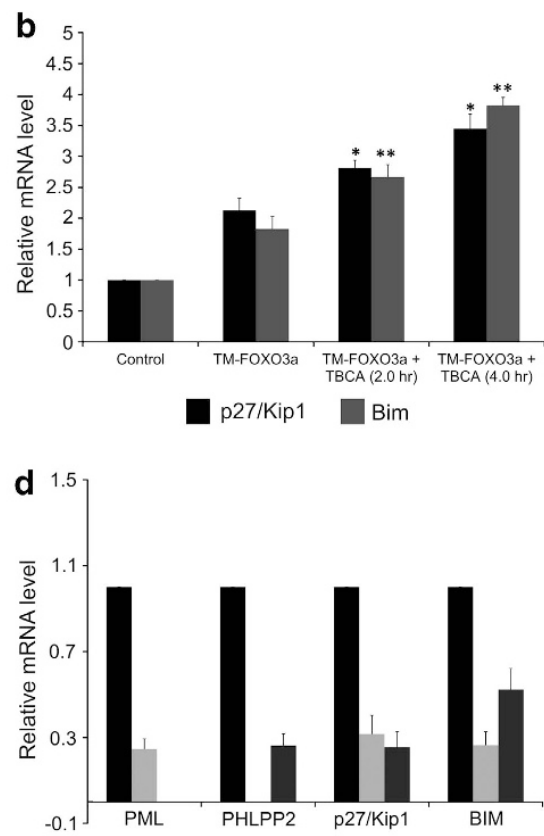

Cont si $\square$ PMLsi $\square$ PHLPP2si e
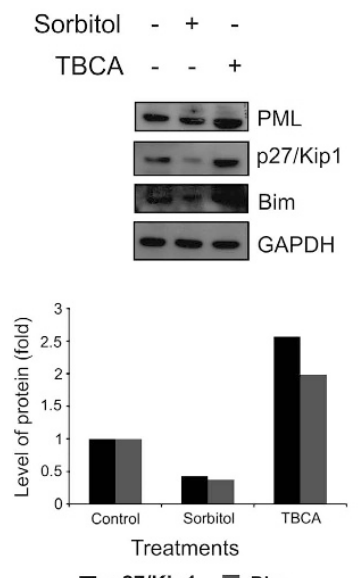

p27/Kip1 Bim f
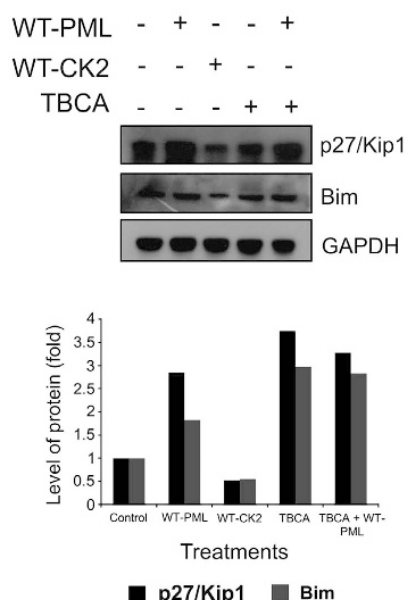

g

Control si + -

PML si - + -

PHLPP2 si - - +
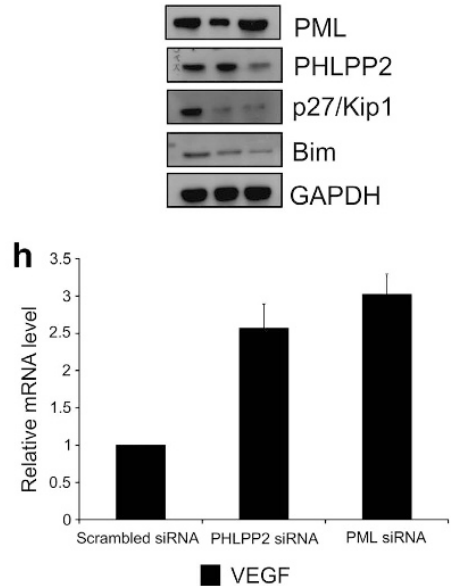

Figure 5 CK2 negatively regulates p27 Kip1 and Bim expression (transcriptional activity of FOXO3a) following the (PML-PHLPP2)—pAKT-FOXO3a signaling axis. (a) CK2 and AKT-S129D, both lowers p27 Kip1 and Bim expression identically, while overexpression of WT-PML and inhibition of CK2 activity had opposite outcomes. qRTPCR analysis of $\mathrm{p} 27^{\mathrm{Kip} 1}$ and Bim mRNA was performed from total RNA extracted from PC3 cells with the mentioned treatments. Figure represents normalized relative mRNA fold change of $\mathrm{p} 27^{K i p 1}$ and Bim. The respective level of significances $\left({ }^{*} P=0.014,{ }^{* *} P=0.021\right)$. (b) AKT refractive form of FOXO3a (TM-FOXO3a) enhances p27 ${ }^{K i p 1}$ and Bim transcription, which is further intensified upon CK2 inhibition. qRT-PCR analysis of p27 $7^{K i p 1}$ and Bim mRNA was performed from total RNA extracted from PC3 cells transfected with TM-FOXO3a and treated with TBCA after $36 \mathrm{~h}$ post-transfection. Figure represents normalized relative mRNA fold change of p27 ${ }^{\text {Kip1 }}$ and Bim. The respective level of significances ( ${ }^{\star} P=0.017,{ }^{\star \star} P=0.012$ ). (c) Luciferase assay to demonstrate the promoter activity of p2 ${ }^{K i p 1}$ gene. PC3 cells were transfected with the pGVB2-p27 ${ }^{K i p 1}$-promLuc construct along with Renilla reporter construct, serving as transfection control. After $24 \mathrm{~h}$, the transfected cells were either transfected or treated or both (as indicated). The figure represents relative fold change in Luciferase readings, normalized against Renilla reporter activity depicted at the level of significance $\left({ }^{\star} P=0.019\right)$. TBCA was treated for the indicated duration after $32 \mathrm{~h}$ post-transfection (in all the cases otherwise mentioned). (d) Downregulation of both PML and PHLPP2 has negative effect on p27 ${ }^{K i p 1}$ and Bim transcriptional expression. qRT-PCR analysis of $\mathrm{p} 27^{\text {Kip1 }}$ and Bim mRNA was performed from total RNA extracted from PC3 cells after knocking down of PML and PHLPP2. Figure represents normalized relative mRNA fold change of $p 27^{K i p 1}$ and Bim. (e) Protein levels of $p 27^{K i p 1}$ and Bim decreases upon CK2 activation, while is regained once CK2 is inhibited. Figure represents, IB analysis with the mentioned antibodies was performed with WCL from PC3 cells treated with either $d-$ Sorbitol or TBCA. (f) Protein levels of p27 $7^{K i p 1}$ and Bim depicts antagonistic pattern upon exogenous overexpression of CK2 and PML. PC3 cells were transfected with either WT-CK2 $\alpha$ or WT-PML or treated with TBCA; cell lysates were analyzed by IB by probing with indicated antibodies. (g) Both PML and PHLPP2 knockdown abates the protein level expression of p27 ${ }^{\text {Kip } 1}$ and Bim. Figure represents, IB analyses performed using PC3 WCL, after transfection with either PML si or PHLPP2 si. (h) qRT-PCR analysis of VEGF mRNA was performed from total RNA extracted from PC3 cells treated with either PML si or PHLPP2 si. In every case, bar represents ( \pm ) S.D. of three independent biological repeats at the mentioned level of significances. Control cells (in $\mathbf{a}, \mathbf{b}, \mathbf{c}, \mathbf{f}$ ) were transfected with appropriate empty vector followed by DMSO treatment in comparable amount 
a

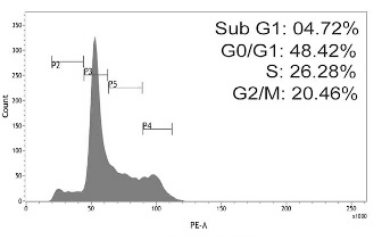

Empty Vector/ $24 \mathrm{hr}$

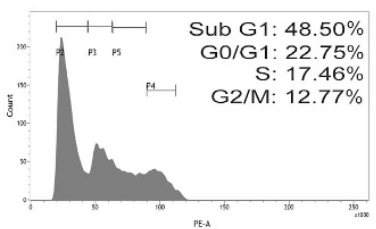

25 uM TBCA/ $24 \mathrm{hr}$

d

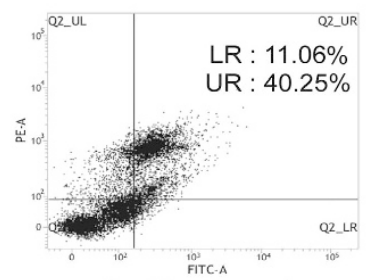

Positive Control

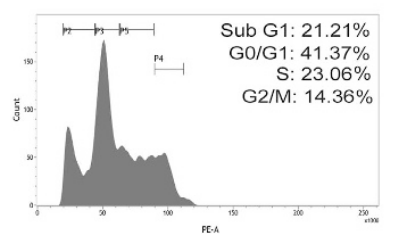

$10 \mathrm{uM}$ TBCA/ $24 \mathrm{hr}$

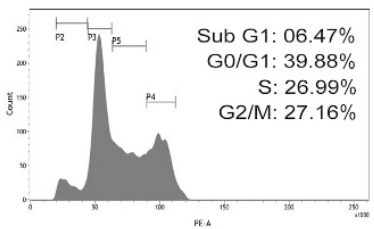

WT-CK2alpha/ $24 \mathrm{hr}$ b

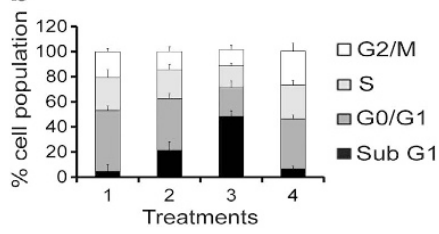

C
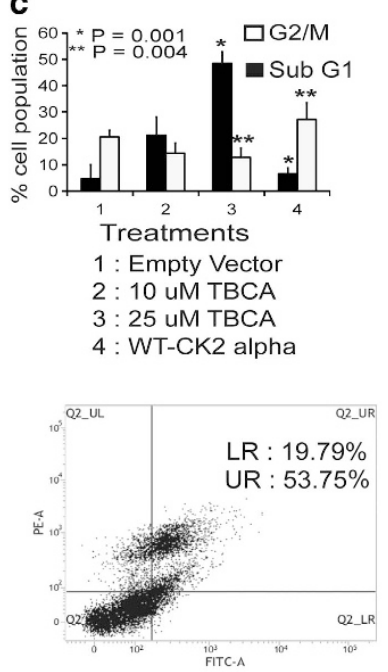

25 uM TBCA

LR : Lower Right UR : Upper Right

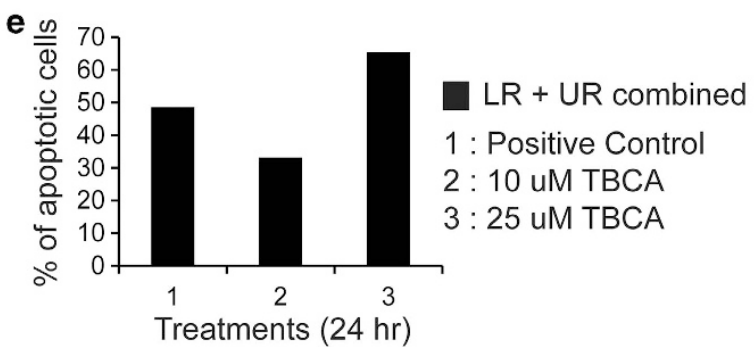

Figure 6 Inhibition of CK2 significantly inflicts growth arrest followed by apoptosis of cancer cells. (a) PC3 cells were either treated with TBCA, or transfected with exogenous WT-CK2 $\alpha$. Cells were appropriately processed for cell-cycle analysis via FACS following transfection or treatment. (b) Comparative quantitation of cell percentage at the different phase of cell cycle. Cells were subjected to either treatment with TBCA or transfected with WT-CK2 $\alpha$. (c) Comparative quantitation, depicting percentage of cell population at sub- $G_{0} / G_{1}$ and $G_{2} / M$ phases of cell cycle upon treating the cells either with TBCA or overexpressing WT-CK2 $\alpha$ by, with the respective level of significance $\left({ }^{\star} P=0.004\right.$ and ${ }^{\star \star} P=0.009$ ). (d) Inhibition of CK2 triggers apoptotic cell death. PC3 cells were treated with TBCA and appropriately processed for Annexin-PI labeling assay. Quadrate plot depicts the percentage of apoptotic cells. The lower right (LR) quadrant houses the early to early-mid apoptotic cells whereas the upper right (UR) quadrant represents cells chiefly at mid to mid-late apoptotic phases. In all, $25 \mu \mathrm{M}$ of Camptothecin-treated cells served as positive control. (e) Comparative quantitation of total apoptotic cell population (both LR and UR) combined at the indicated concentrations of TBCA treatment for $24 \mathrm{~h}$. In every case, bars represent ( \pm ) S.D. of three independent biological repeats at the mentioned level of significances. Control cells were transfected with appropriate empty vector where required, followed by DMSO-water treatment

\begin{abstract}
Protein kinase CK2 is upregulated in in vivo samples of human prostatic carcinoma, while rest of the members in the postulated signaling axis manifests a congruent pattern. Several reports already exist, supporting the importance of CK2 in $\mathrm{PCa}$, with distinct mention about oncogenic influence of nuclear CK2. ${ }^{40}$ In consistent with that we were interested to inspect the protein level of CK2 in human $\mathrm{PCa}$ tissue samples. It is observed that in $\mathrm{PCa}$ tissue, not only the overall protein intensity of CK2 is higher, but also, it is perceptibly nuclear (Figure 7a; Supplementary Information S-6). On the other hand, PML
\end{abstract}

had been reported to have reduced level of expression in multiple neoplasia, ${ }^{41}$ and we too found that PML protein expression is significantly lower in $\mathrm{PCa}$ samples, in comparison to $\mathrm{PHp}$, where it manifests an intense nuclear staining (Figure 7a; Supplementary Information S-6). pAKT(S473) and pFOXO3a(S253) both illustrated a profuse nuclear staining pattern in PCa samples, having rather a low and non-nuclear staining patterns in $\mathrm{PHp}$ samples (Figure 7a; Supplementary Information S-6), which is in consistence with our proposed hypothesis and also in accordance to established findings. ${ }^{42}$ Upon quantification, 

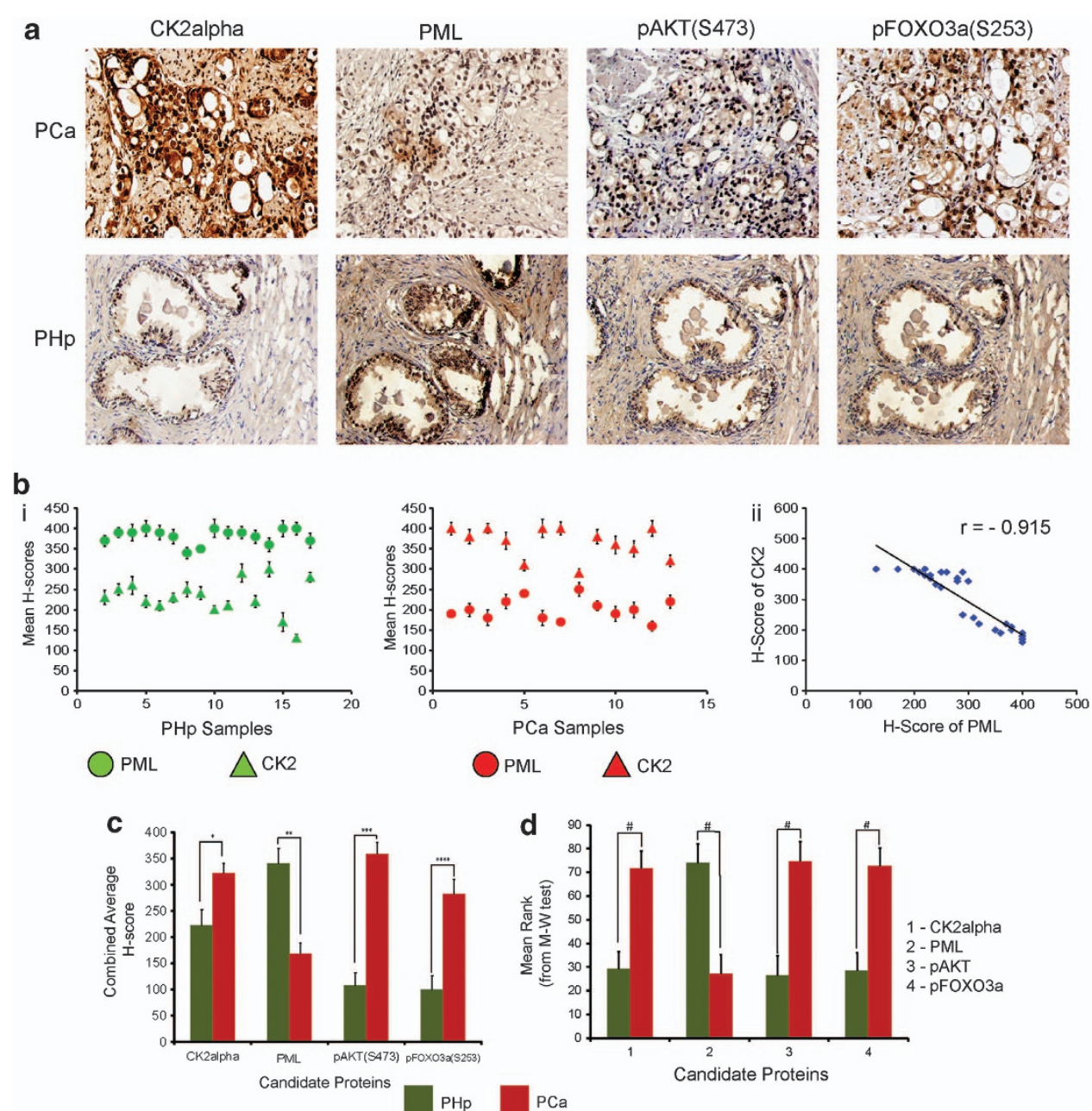

\begin{tabular}{|c|c|c|}
\hline Proteins & U-PCa & U-PHp \\
\hline CK2 & 188.5 & 2311.5 \\
\hline PML & 2369 & 81 \\
\hline PAKT (S473) & 44.51 & 2455.5 \\
\hline pFoxO3a (S253) & 143.5 & 2365.5 \\
\hline
\end{tabular}

Mann-Whitney (M-W) - 'U' test statistics

Figure 7 Protein kinase CK2 is upregulated in PCa while PML has a low expression, rest of the members in the postulated signaling axis manifests a congruent picture. (a) Representative IHC images of the candidate proteins involved in the signaling axis, viz;; CK2 (CK2 $\alpha$ ), PML, pAKT(S473) and pFOXO3a(S253) in PCa and PHp tissue samples. (b) (i) Scattered plot, representing the mean $\mathrm{H}$-scores of respective PCa and PHp tissue samples, (ii) Depiction of correlation coefficient ( $r$ ) between mean $\mathrm{H}$-scores of CK2 and PML estimated from IHC images of both PCa and PHp tissues combined. (c) Comparison of combined average H-scores of CK2 $\alpha$, PML, pAKT(S473) and pFOXO3a(S253). The bars represent the mean $\left( \pm\right.$ ) S.D. of independent two-tailed Student's t-tests, where ${ }^{\star} P=0.027,{ }^{* \star} P=0.004,{ }^{* \star *} P=0.039$ and ${ }^{* \star \star \star} P=0.016$ are the respective level of significances. The quantitative depictions of Mann-Whitney U-test (M-W U-test). (d) Graphical representation of mean ranks of the observed individual $H$-scores of each candidate proteins as obtained through calculations from M-W $U$ - test. The observed ${ }^{\#} P$-value is $<0.001$. (e) Table displaying the calculated ' $U$ ' values for the $\mathrm{H}$-scores of each observed proteins

the staining intensities of CK2 and PML, depicts significant difference between PCa and PHp tissues (Figure 7b); moreover, when statistically analyzed, a robust degree of negative correlation $(r=-0.915)$ was revealed between them, which again confirms the importance of CK2-mediated degradation of PML. When the staining intensity of all the proteins in the postulated signaling axis [CK2-(PML-PHLPP2)-pAKT-FOXO3a] were estimated to be analyzed alongside, each of them depicted a significant increase in staining intensity in $\mathrm{PCa}$ samples when compared with $\mathrm{PHp}$ tissues (Figure 7c). The MannWhitney $U$-test predicts that the difference of $\mathrm{H}$-scores between $\mathrm{PCa}$ and $\mathrm{PHp}$ samples are indeed statistically significant (Figures $7 d$ and e). 


\section{Discussion}

The oncogenic influence of protein kinase CK2 has been emphasized consistently in the recent pasts, ${ }^{43}$ strongly revealing the vital influences of CK2 activity in various neoplasias. ${ }^{44}$ Ample researches have revealed that PCas are particularly predisposed towards upregulated CK2 and its consequential effects to such an extent that hampering CK2 signaling is enough to elicit apoptosis in $\mathrm{PCa}{ }^{45}$ The aspect that demands special attention in recent times is the pro-oncogenic affairs of nuclear CK2; especially in the context of PCa. ${ }^{40}$ Tumor suppressor PML has emerged as a crucial target of thorough investigation since it has been demonstrated that CK2 evokes precocious destruction of PML, ${ }^{19}$ curbing its vital role in prohibiting oncogenic transpositions of normal cell, ${ }^{17}$ and control of apoptosis. ${ }^{46}$ Supported by the fact that PML is predominantly modified by post-translational processes in multitudinous human malignancies, ${ }^{18}$ here we reinforce that CK2-mediated degradation of PML occurs in PCa too (both cell and tissue). We have successfully identified a second phosphatase isoform (PHLPP2) of AKT to be interacting with PML in PML-NBs, which foster the tumor suppressive activity of PML by supplementing the previously described PML-PP2a coalition. ${ }^{22}$ We have also depicted that PML-PHLPP2 conglomerate convincingly leads to dephosphorylation of AKT inside the nucleus thereby rendering it inactive, accounting the importance of Ser473 dephosphorylation. PHLPP2 already possess a strong reputation for tumor prevention by moderating AKT/PKB ${ }^{27,47}$ and our findings will strengthen its pre-existing repute. In relation with the prominent role of AKT in prostatic neoplasia ${ }^{42}$ we illustrated that deactivating nuclear AKT, renounces nuclear FOXO3a, which happens due to AKT-mediated phosphorylation on multiple Serine and Threonine residues. ${ }^{34}$ Moreover, since bulk of our present investigation involves androgen-independent PCa cells (PC3), the involvement of AKT signaling in the context of androgen impassiveness is re-emphasized. ${ }^{48}$ FOXO3a already possess a convincing repute as tumor suppressor in $\mathrm{PCa}^{49-51}$ our study will strengthen the fact in the scenario of androgen-independent PCa. In summary, our data confer convincing evidence, that CK2 plays a decisive role in maintenance and progression of androgen-independent PCas by promoting precocious destabilization of PML and which effectively revokes the novel association between PML and PHLPP2. The eventual outcome of which is the perpetuation of AKT activity inside the nucleus preventing $\mathrm{FOXO} 3 a$ activity. Inhibition of CK2 substantially hampers cancer cell migration, proliferation and even induces apoptosis. Although CK2 has been already a target for $\mathrm{PCa}$ therapy, much of its behavior in relation to PML and AKT is still unknown, so do the PML-PHLPP2 coalition dynamics. Analysis of human PCa samples ratifies our hypothesis, evoking a potential possibility of future therapeutic intervention constituting a combination of specific small molecule inhibitor of $\mathrm{CK} 2$ and ionizing radiations, which is reported to augment cellular FOXO3a level ${ }^{52}$ in the treatment of androgen refractory prostatic carcinoma where AKT plays a pivotal role. Our investigation elucidates an important aspect of cancer cell signaling, by describing the well-orchestrated [CK2—(PML-PHLPP2)—-pAKT—FOXO3a] (Figure 8) signaling network axis, that cancer thrives on multiple delicate intermolecular conjunctions, which have evolved complexity to sustain oncogenicity, but at the same time could well expose the much coveted 'Achilles' heel' of cancer.

\begin{abstract}
Materials and Methods
Human prostate tissue samples. Formalin-fixed paraffin-embedded (FFPE) post-surgical human prostate tissue samples were collected from patients diagnosed with either prostatic carcinoma $(\mathrm{PCa}, N=13)$ or benign prostatic hyperplasia ( $\mathrm{PHp}, \mathrm{N}=18$ ) confirmed by prostatic biopsy and other clinicopathological tests, following all medical and ethical regulations, and with formal approval from the ethical committee of both CSIR-IICB and Park Clinic (source). The modal age is 66 years, the range being $61-69$ years.
\end{abstract}

Immunohistochemistry (IHC) and image scoring. For the purpose of immunohistochemical staining, $5 \mu \mathrm{m}$ thick sections were obtained from FFPE blocks followed by antigen retrieval using Citrate Buffer ( $\mathrm{pH}$ 6.0). Primary antibodies were incubated overnight at $4{ }^{\circ} \mathrm{C}$ at a dilution of $1: 200$ in all the cases. HRP-linked secondary antibodies were incubated for $2 \mathrm{~h}$ at a dilution of 1:500. 3, 3Diaminobenzidine (DAB) reagent (\#550880; BD Pharmingen, San Jose, CA, USA) was used to detect the positivity of the staining. Mayer's Hematoxylin (\#MHS1; Sigma, St. Louis, MO, USA) was used as a counter stain for nucleus. Mounted slides were viewed under microscope (BX61, Olympus, Tokyo, Japan) using X200 and X600 OI magnification. Images were captured using DP71 (Olympus) camera and Image Pro Plus imaging software (Media Cybernetics, Bethesda, MD, USA). A semiquantitative scoring method ${ }^{53}$ was employed for assessing the intensity of staining described as follows. Multiple randomly chosen fields were captured from each section of both PCa and PHp to assess equal number of glandular cells (1000 in our case), degree of staining ranging from $0-100 \%$, which were multiplied by the dominant intensity pattern of staining (1, negative or trace; 2 , weak; 3 , moderate; 4 , intense). Therefore, an overall $\mathrm{H}$-score ranging from $0-400$ was achieved. Cell nuclei with scores $0-200,201-300$, and 301-400 were categorized as having negative or low, intermediate, and high levels of expression, respectively. The mean $\mathrm{H}$-score was calculated for each slide and incorporated for further statistical analysis. Two observers (AC and $\mathrm{UC}$ ) independently evaluated the immunostaining results. The concordance ratio was $>95 \%$. A consensus assessment was obtained by endorsing the opinion of a third evaluator (MKG). Since the phenomenon mentioned in our study chiefly concentrates on the nuclear action of CK2, and rest of the proteins (viz. PML, pAKTS473 and pFOXO3aS253) are predominantly nuclear, so only positive staining for nucleus have been taken into consideration for all sorts of quantitation and Image scoring.

Fluorescence-immunohistochemistry. For the purpose of fluorescence-immunohistochemical staining, standard protocol of IHC was followed (as described above) with some necessary modifications. Secondary antibodies were fluorochrome-conjugated and tissues were incubated for $2 \mathrm{~h}$ at a dilution of $1: 500$ in a humidified chamber under darkness. Slides were finally mounted by cover slips with Fluoroshield DAPI and viewed under microscope (BX61, Olympus) using X600 OI magnification. Images were captured using DP71 (Olympus) camera with Image Pro Plus imaging software (Media Cybernetics).

Cell culture, transfections and treatments. HEK293 and PC3 human PCa cells were procured from ATCC (Manassas, VA, USA) and cultured in Dulbecco's Modified Eagle's Medium (DMEM) (Gibco, Life Technologies, Grand Island, NY, USA), supplemented with 10\% fetal bovine serum (FBS) (Invitrogen, Life Technologies, Grand Island, NY, USA) maintained at $5 \% \mathrm{CO}_{2}$ and $37^{\circ} \mathrm{C}$.

Penicillin/Streptomycin (Invitrogen, Life Technologies) cocktail and Gentamycin (Invitrogen, Life Technologies) were added as prescribed antibiotic at the recommended dose.

For HEK293 cells, calcium phosphate method as described previously ${ }^{54}$ while for PC3 cells, Lipofectamine 2000 reagent (\#18324012; Invitrogen) was used for transfection of plasmid DNAs.

For siRNA transfection (100 pmol/well), HiPerFect reagent (\#301705; Qiagen, Valencia, CA, USA) was used in all cases.

Transfection of plasmids were followed up to $36 \mathrm{~h}$, while in the case of siRNA, $72 \mathrm{~h}$ was determined as the optimum time limit. 


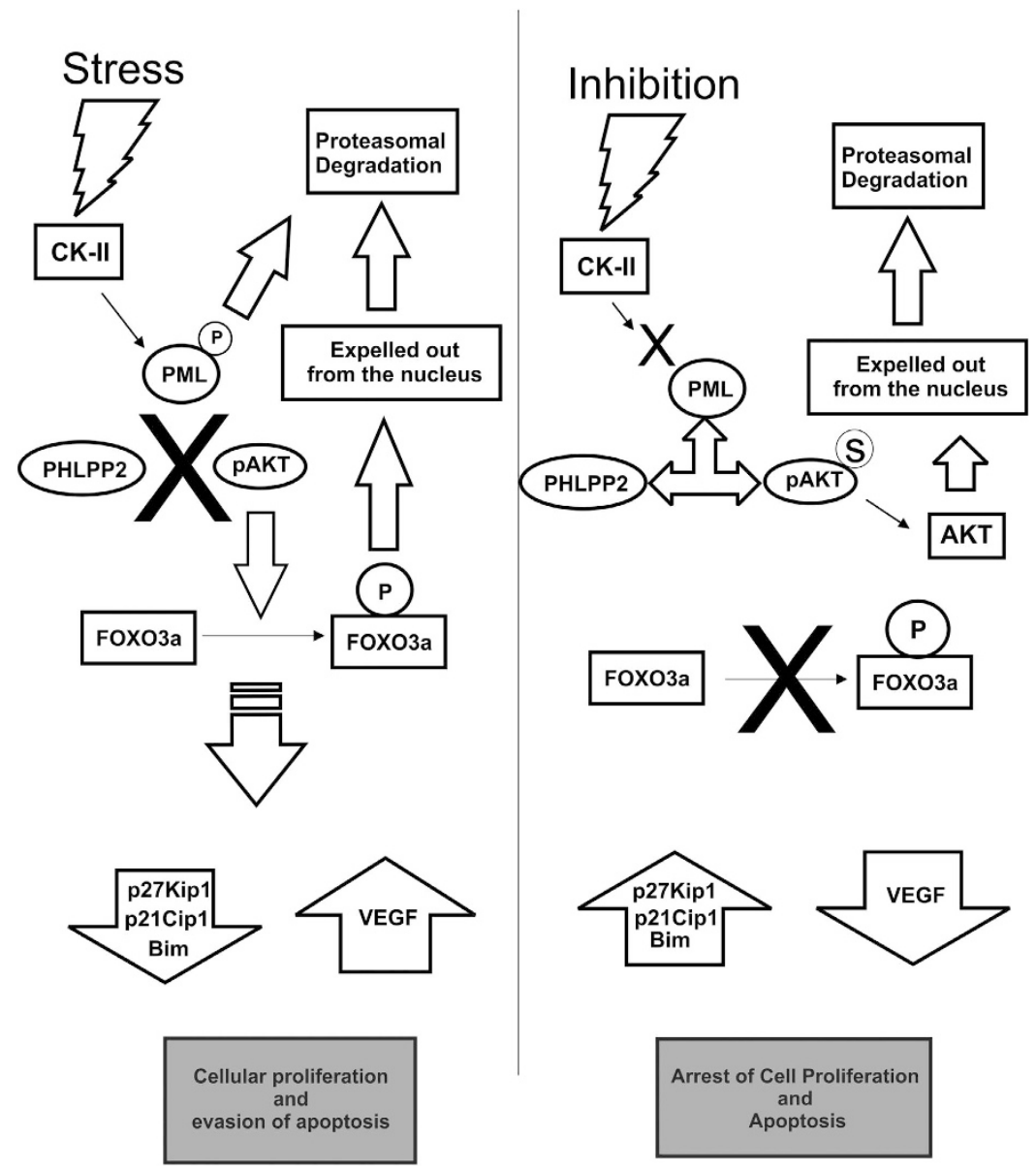

Figure 8 Model depicting the network of signaling dynamics leading to nuclear exclusion of FOXO3a by protein kinase CK2. In stress situations, protein kinase CK2 gets activated and inflicts untimely phosphorylation guided proteasomal degradation of PML. CK2 phosphorylates PML at Ser517 residue (the residue is located within the phospho-degron of $\mathrm{PML}^{20}$ ), promoting it for proteasomal degradation. Hence, $\mathrm{PML}$ is unable to provide the scaffolding/docking platform for the functional interaction of activated AKT (pAKT) and its phosphatase (here PHLPP2) inside the nucleus. The effect of which is the continual aberrant activity of nuclear AKT. As a potent oncogenic signature, active AKT phosphorylates tumor suppressor FOXO3a expelling it out from the nucleus. ${ }^{25}$ FOXO3a being an eminent tumor suppressive transcription factor, its

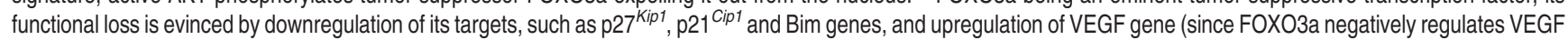
expression). The net result of which is manifested in the form of heightened cellular proliferation and reduced apoptosis. The above-described signaling interplay along with cellular phenotypic effects gets completely reversed when CK2 is inhibited

TBCA (\#218710; specific small molecule inhibitor of CK2) ${ }^{55}$ and LY294002 (\#440202; specific small molecule inhibitor of PI3K/AKT pathway) treatment was done for $2 \mathrm{~h}$ at the dose of 10 and $20 \mu \mathrm{M}$, respectively, in all experiments or otherwise mentioned separately. In all, $0.5 \mathrm{M} d-$ Sorbitol (in water) for $1 \mathrm{~h}$ was used to stimulate CK2 activity as it has been described previously ${ }^{19}$ in all experiments wherever it was necessary. Cycloheximide (translational blocker, \#239764; Calbiochem, Darmstadt, Germany) treatment was offered for $4 \mathrm{~h}$ at a concentration of $25 \mu \mathrm{M}$ everywhere, else have been mentioned separately. MG132 (Proteasome inhibitor, \#474790; Calbiochem, Germany) was treated for $4 \mathrm{~h}$ at a concentration of $25 \mu \mathrm{M}$.

Expression plasmids. pGZdx21-GFP-CK2 $\alpha$ plasmid construct was generated through subcloning from pcDNA6.1-WT-CK2 $\alpha$-V5-His plasmid construct. (In every experiment, both pGZdx21-GFP-CK2 $\alpha$ construct and pcDNA6.1-WT-CK2 $\alpha$ V5-His construct has been abbreviated as WT-CK2 $\alpha$ only, otherwise separately mentioned). pGZdx21-AKT1-(S129D)-GFP plasmid construct was generated from pGZ-AKT1-GFP (cloned from human CDNA) by PCR Stitching method of sitedirected mutagenesis (described separately below). pECE-HA-FOXO3a-TM (T32A, S253A, and S315A, transcriptionally omni-active) plasmid was procured from ADDGENE. All constructs were verified by sequencing.
Site-directed mutagenesis (SDM) by PCR method (Stitching Method). The protocol is adapted from Ho et al. ${ }^{56}$ In brief, at first two different PCR reactions were ran, one containing the subcloning forward primer (with restriction enzyme site) and mutagenic reverse primer, the other containing the subcloning reverse primer and mutagenic forward primer. The PCR products were subsequently ran and isolated from soft agarose gel. The concentration of the isolated products were spectrophotometrically determined and mixed into 1:1 ratio, $100 \mathrm{ng}$ each. Another PCR reaction was ran with this mixture and this time subcloning forward and reverse primers were used. The product from this reaction was similarly gel isolated and used for ligation and transformation subsequently.

Confirmation of the SDM. The mutation was also confirmed by PCR amplification method, where two primers (one serving as the reverse primer for the mutated gene [ $\mathrm{Cr}]$ and the other serving as the forward primer [Cf] of the mutated gene) were designed with the mutated nucleotide(s) at their $3^{\prime}$ ends. Two separate PCR reactions were ran with either subcloning forward primer (AF) and subcloning reverse primer $(\mathrm{AR})$ in the required combinations with the mutated $3^{\prime}$ end primers $(\mathrm{Cf}$ and $\mathrm{Cr})$.

Negative control PCR reactions were ran with primers having original/unmutated nucleotide(s) at their $3^{\prime}$ ends (Wf and Wr). Confirmatory result yielded two products 
of different sizes (417 and $1089 \mathrm{bps}$ ) while there were absolutely no amplifications in the negative control reactions. The representative picture of the agarose gel with the PCR products is provided as Supplementary Information (S-2b). The primer sequences used for both SDM and confirmation has been provided in a separate table given in the same supplementary Information (S2-a). Apart from this, the mutation was also confirmed by sequencing methods, which not only confirmed the mutation, but also supported the PCR method of SDM confirmation to be valid and applicable.

In vitro Scratch-Assay. Cells were seeded at the recommended density into $35-\mathrm{mm}$ culture dishes so that they reach near confluency after $24 \mathrm{~h}$. After which, fine but detectable scratches were made through the cells using sterile tips. Cells were observed under low power objectives $(\times 4$ and $\times 10)$ in the following day to assess the extent of migration through the scratches. ${ }^{57}$

Immuno-fluorescence microscopy. HEK293 and PC3 cells were plated over sterile cover slips placed inside 35-mm tissue culture dishes and cultured in prescribed condition and standard protocol of immunostaining was followed. Mentioned primary antibodies, followed by fluorochrome-conjugated secondary antibodies (refer to Supplementary Figure S1) were incubated at appropriate dilution and duration. 4, 6-diamino-2-phenylindole (DAPI-blue) served as appropriate nuclear counter stain. All slides were viewed under microscope (BX61, Olympus) in X600 OI magnification. Images were captured using DP71 camera (Olympus) and Image Pro Plus imaging software (Media Cybernetics).

For the time-lapse co-localization experiment, cells were treated with appropriate drugs for defined time points. Cells were then fixed, processed and viewed for fluorescence as stated above. Pixel co-localization and coefficient of co-localization at various time points were determined using JACoP v2.0 in Image $\mathrm{J}$ software (http://rsbweb.nih.gov).

Co-immunoprecipitation (Co-IP) and immunoblot (IB) analyses. Prior to harvesting, cells were washed twice with ice cold $1 \times$ PBS, spun down and re-suspended in Tris lysis buffer ( $(50 \mathrm{mM}$ Tris/HCl pH 7.5, $150 \mathrm{mM}$ $\mathrm{NaCl}, 1 \%$ Triton X-100, $1 \mathrm{mM}$ DTT, $1 \mathrm{mM} \mathrm{Na} \mathrm{VO}_{4}, 30 \mathrm{mM}$ B-glycerophosphate, $10 \mathrm{mM} \mathrm{NaF}$ and $0.1 \mathrm{M}$ Phenylmethanesulfonylfluoride (PMSF)) containing protease inhibitor cocktail (\#539136; Calbiochem, Billerica, MA, USA). The whole-cell lysates thus obtained were photometrically quantified and subjected to SDS-PAGE, followed by IB. For preparation of CE/NE extract cells were harvested as described above and then first re-suspended in harvest buffer containing $10 \mathrm{mM}$ HEPES (pH 7.9), $50 \mathrm{mM} \mathrm{NaCl}, 0.5 \mathrm{M}$ Sucrose, $0.1 \mathrm{mM}$ EDTA, 0.5\% TritonX 100 and protease inhibitor cocktail (Calbiochem, USA). After obtaining the cytoplasmic extract, the pellet was washed thrice with wash buffer/Buffer A (10 mM HEPES (pH 7.9), $10 \mathrm{mM} \mathrm{KCL}, 0.1 \mathrm{mM}$ EDTA and 0.1 mM EGTA), then resuspended in Buffer $\mathrm{C}(10 \mathrm{mM}$ HEPES $(\mathrm{pH} 7.9), 500 \mathrm{mM} \mathrm{NaCl}, 0.1 \mathrm{mM}$ EDTA, $0.1 \mathrm{mM}$ EGTA, $0.1 \%$ NP40 and protease inhibitor cocktail (Calbiochem, USA) to extract the nuclear proteins.

For IB analyses, respective primary antibodies were used in $1: 1000$ dilutions in $1 \%$ BSA in TBS-T, and HRP-tagged secondary antibodies were incubated at a dilution of $1: 2000$ also in $1 \%$ BSA in TBS-T. For primary antibody, overnight incubation at $4{ }^{\circ} \mathrm{C}$ was used, and for secondary antibody, $2 \mathrm{~h}$ incubation at RT was followed.

For IPs, cells were harvested in IP Lysis Buffer (50 mM HEPES, pH 7.2, $250 \mathrm{mM}$ $\mathrm{NaCl}, 10 \%$ glycerol, $1 \%$ Nonidet P-40, 1.0 mM EDTA, 0.5 mM DTT,0.1 M PMSF and protease inhibitor cocktail (Calbiochem, USA). In all, $1 \mathrm{mg}$ of total protein was used for actual IP in all cases. The rest of the IP procedure was performed as per standard protoco ${ }^{50}$ using Protein A Sepharose CL-4B beads (\#17-0780-01; GE Healthcare, Piscataway, NJ, USA).

RNA preparation and quantitative real-time PCR. Total RNA was extracted from HEK293 and PC3 cells by using Trizol reagent (\#15596-026; Invitrogen) as per the manufacturer's protocol. cDNA was prepared by using RevertAid First-Strand cDNA Synthesis Kit (\#K1622; Fermentas, Glen Burnie, MD, USA) as per the manufacturer's protocol. For qRT-PCR analysis, $1.0 \mu \mathrm{l}$ from each cDNA sample was used as template. Real-time PCR was performed using Fast SYBR Green Master Mix (\#4385617; Applied Biosystems, Foster City, CA, USA) in 7500-Fast Real-Time PCR Instrument (Applied Biosystems) according to the manufacturer's instructions. Each sample was analyzed in at least three independent assays. Mean values of the gene of interest were normalized against 18s rRNA levels (used as endogenous reference in all the cases, otherwise mentioned). The primer sequences have been provided separately as Supplementary Information S2-a.
Luciferase assay. HEK293 cells were transiently transfected with $2.0 \mu \mathrm{g}$ of WWP-p21/Waf1-Luc (procured from ADDGENE) and pGVB2-p27 ${ }^{\text {Kip1 }}$-Luc reporter constructs along with respective plasmid constructs of genes as per experimental interest (detailed description is provided in Results) and $100 \mathrm{ng}$ of Renilla luciferase vector (pRL-TK) in all cases and cultured for $50 \mathrm{~h}$. After that cells were treated with respective inhibitors and stimulators for the requisite durations (mentioned above, described in the respective legend). Luciferase Assay was performed with the cell lysates $36 \mathrm{~h}$ ( $60 \mathrm{~h}$ in total) post-transfection following the manufacturer's protocol. Luciferase activity was assessed using Dual Luciferase Reporter Assay System (\#E1910; Promega, Madison, WI, USA) and measured in VICTOR X Multilabel Plate Readers (Perkin-Elmer, Waltham, MA, USA). Quantification was based on three independent experiments.

Cell-cycle analysis and Annexin-V labeling assay. PC3 cells were either treated with respective inhibitors and stimulators (see figure legend) or transfected with WT-CK2 $\alpha$ DNA for the requisite durations and were harvested using $0.25 \%$ Trypsin. For cell-cycle analysis, cells were then processed as per standard protocol, incubated with PI-RNase solution (\#550825; BD Pharmingen, San Jose CA, USA) and analyzed in FACS Verse Instrument using FACS Suite Software (BD Bioscience, San Jose, CA, USA). For transfection, $4.0 \mu \mathrm{g}$ of pGZdx21-GFP-CK2 $\alpha$ plasmid DNA construct was used. For Annexin-V labeling Assay, cells were harvested after respective treatments (described in legends) and processed as per the manufacturer's protocol. Annexin-V FITC antibody was procured from BD Pharmingen (\#560931). Analysis was performed in FACS Verse Instrument using FACS Suite Software (BD Bioscience, San Jose, CA, USA). Figure supplied is the best of three individual experiments, while quantification was based on all of them.

Statistical analyses. Paired Student's t-test was employed to determine the significance value in all other experiments (even if not mentioned separately). The evaluation of the differences in $\mathrm{H}$-score values of all the concerned proteins between $\mathrm{PCa}$ and $\mathrm{PHp}$ tissues were carried out by Mann-Whitney U-test. The correlation test was employed to evaluate correlation between CK2-PML protein expression levels (individual $\mathrm{H}$-scores) in both $\mathrm{PCa}$ and $\mathrm{PHp}$ tissues and coefficient of correlation $(r)$ was estimated. All statistical analyses were performed using either PSPP (GNUGSL, Boston, MA, USA) or Graph Pad Prism (Graph Pad Prism, San Diego, CA, USA) statistical software packages. In every case, the value of $P<0.05$ was considered to be statistically significant, otherwise mentioned. Data are reported as mean values $( \pm)$ S.D. of at least three independent experiments (mentioned otherwise).

\section{Conflict of Interest}

The authors declare no conflict of interest.

Acknowledgements. The above study was conducted from the financial support provided by Council of Scientific and Industrial research (CSIR-EMPOWER/ OLP-002), Government of India, and Department of Science and Technology (DST-SR/SO/HS-150/2010), Government of India. We are sincerely thankful and obliged to the following scientists, for their valuable support: Dr. Khalil Ahmed; Masonic Cancer Center, University of Minnesota, Minneapolis, MN, USA, for kindly gifting us with the pcDNA6-CK2alpha-V5-His plasmid DNA construct. Dr. Paul S Freemont; Division of Molecular Biosciences, Imperial College of London, UK, for kindly gifting us with the pSG5-FLAG-PML plasmid DNA construct. Dr. Toshiyuki Sakai; Department of Molecular-Targeting Cancer Prevention, Graduate School of Medical Science, Kyoto Prefectural University of Medicine, Kawaramachi-Hirokoji, Kamigyo-ku, Kyoto, Japan, for kindly gifting us with the pGVB2-p27Kip1-Luc promoter construct.

1. Hanahan D, Weinberg RA. Hallmarks of cancer: the next generation. Cell 2011; 4: 646-674.

2. Sayyed KZ, Daniel WY, Amjad J, Jitesh P, Martin M, Andre van W et al. Nuclear microenvironments in biological control and cancer. Nat Rev Cancer 2007; 7: 454-463.

3. Mosser DD, Morimoto RI. Molecular chaperones and the stress of oncogenesis. Oncogene 2004; 23: 2907-1298.

4. Hoeller D, Hecker CM, Dikic I. Ubiquitin and ubiquitin-like proteins in cancer pathogenesis. Nat Rev Cancer 2006; 6: 776-788. 
5. Esquela-Kerscher A, Slack FJ. Oncomirs-microRNAs with a role in cancer. Nat Rev Cancer 2006; 6: 259-269

6. Zhang J, Yang PL, Gray NS. Targeting cancer with small molecule kinase inhibitors. Nat Rev Cancer 2009; 9: 28-39.

7. Pinna LA. A historical view of protein kinase CK2. Cell Mol Biol Res. 1994; 40: 383-390.

8. Allende JE, Allende CC. Protein kinases. 4. Protein kinase CK2: an enzyme with multiple substrates and a puzzling regulation. FASEB J 1995; 9: 313-323.

9. Litchfield DW, Luscher B. Casein kinase II in signal transduction and cell cycle regulation. Mol Cell Biochem 1993; 127-128: 187-199.

10. Ahmed $\mathrm{K}$, Gerber DA, Cochet $\mathrm{C}$. Joining the cell survival squad: an emerging role for protein kinase CK2. Trends Cell Biol 2002; 12: 226-230.

11. Ahmed K, Davis AT, Wang H, Faust RA, Yu S, Tawfic S. Significance of protein kinase CK2 nuclear signaling in neoplasia. J Cell Biochem 2000; 35: 130-135.

12. Ahmad KA, Wang G, Unger G, Slaton J, Ahmed K. Protein kinase CK2 $\alpha$ key suppressor of apoptosis. Adv Enzyme Regul 2008; 48: 179-187.

13. Trembley JH, Wang G, Unger G, Slaton J, Ahmed K. Protein kinase CK2 in health and disease: CK2: a key player in cancer biology. Cell Mol Life Sci 2009; 66: 1858-18567.

14. Yu S, Wang H, Davis A, Ahmed K. Consequences of CK2 signaling to the nuclear matrix Mol Cell Biochem 2001; 227: 67-671.

15. Faust M, Montenarh M. Subcellular localization of protein kinase CK2. A key to its function? Cell Tissue Res 2000; 301: 329-340.

16. Guo C, Davis AT, Yu S, Tawfic S, Ahmed K. Role of protein kinase CK2 in phosphorylation of nucleosomal proteins in relation to transcriptional activity. Mol Cell Biochem 1999; 191: 135-142.

17. Salomoni P, Pandolfi PP. The role of PML in tumor suppression. Cell 2002; 108: 165-170.

18. Chen RH, Lee YR, Yuan WC. The role of PML ubiquitination in human malignancies, J Biomed Sci 2012; 19: 81

19. Scaglioni PP, Yung TM, Cai LF, Erdjument-Bromage H, Kaufman AJ, Singh B et al. A CK2-dependent mechanism for degradation of the PML tumor suppressor. Cell 2006; 126: 269-283.

20. Rego EM, Wang Z-G, Peruzzi D, He L-Z, Cardo CC, Pandolfi PP. Role of promyelocytic leukemia (Pml) protein in tumor suppression. J Exp Med 2001; 193: 521-530.

21. Bernardi R, Pandolfi PP. Structure, dynamics and functions of promyelocytic leukaemia nuclear bodies. Nat Rev Mol Cell Biol 2007; 8: 1006-1016.

22. Trotman LC, Alimonti A, Scaglioni PP, Koutcher JA, Cardo CC, Pandolfi PP. Identification of a tumour suppressor network opposing nuclear Akt function. Nature 2006; 441: 523-527.

23. Brazil DP, Yang ZZ, Hemmings BA. Advances in protein kinase $B$ signaling: AKTion on multiple fronts. Trends Biochem Sci 2004; 29: 233-242.

24. Brunet A, Bonni A, Zigmond MJ, Lin MZ, Juo P, Hu LS et al. Akt promotes cell survival by phosphorylating and inhibiting a Forkhead transcription factor. Cell 1999; 96: 857-868.

25. Tran H, Brunet A, Griffith EC, Greenberg ME. The many forks in FOXO's road. Sci STKE 2003; 2003: RE5.

26. Hong ZY, Lee HJ, Shin DY, Kim SK, Seo M, Lee EJ. Inhibition of Akt/FOXO3a signaling by constitutively active FOXO3a suppresses growth of follicular thyroid cancer cell lines. Cancer Lett 2012; 314: 34-40.

27. Gao T, Furnari F, Newton AC. PHLPP: a phosphatase that directly dephosphorylates Akt, promotes apoptosis, and suppresses tumor growth. Mol Cell 2005; 18: 13-24

28. Brognard J, Sierecki E, Gao T, Newton AC. PHLPP and a second isoform, PHLPP2, differentially attenuate the amplitude of Akt signaling by regulating distinct Akt isoforms. Mol Cell 2007; 25: 17-31.

29. Litchfield DW. Protein kinase CK2: structure, regulation and role in cellular decisions of life and death. Biochem J 2003; 369: 1-15

30. Yefi R, Ponce DP, Niechi I, Silva E, Cabello P, Rodriguez DA et al. Protein kinase CK2 promotes cancer cell viability via up-regulation of cyclooxygenase-2 expression and enhanced prostaglandin E2 production. J Cell Biochem 2011; 112: 3167-3175.

31. Wang G, Ahmad KA, Unger G, Slaton JW, Ahmed K. CK2 signaling in androgen-dependent and -independent prostate cancer. J Cell Biochem 2006; 99: 382-391.

32. Kim D, Chung J. Akt: versatile mediator of cell survival and beyond. J Biochem Mol Bio 2002; 35: 106-115.

33. Di Maira G, Salvi M, Arrigoni G, Marin O, Sarno S, Brustolon F et al. Protein kinase CK2 phosphorylates and up regulates Akt/PKB. Cell Death Differ 2005; 12: 668-677.

34. Rena G, Guo S, Cichy SC, Unterman TG, Cohen P. Phosphorylation of the transcription factor forkhead family member FKHR by protein kinase B. J Biol Chem 1999; 274 17179-17183.

35. Dansen TB, Burgering BM. Unravelling the tumor-suppressive functions of FOXO proteins Trends Cell Biol 2008; 18: 421-429.
36. Hauck L, Harms C, Grothe D, An J, Gertz K, Kronenberg G et al. Critical role for FoxO3adependent regulation of $\mathrm{p} 21 \mathrm{CIP} 1 / \mathrm{WAF} 1$ in response to statin signaling in cardiac myocytes. Circ Res 2007; 100: 50-60.

37. Karadedou CT, Gomes AR, Chen J, Petkovic M, Ho K-K, Zwolinska AK et al. FOXO3a represses VEGF expression through FOXM1-dependent and independent mechanisms in breast cancer. Oncogene 2012; 31: 1845-1858.

38. Gao H, Ouyang X, Banach-Petrosky W, Borowsky AD, Lin Y, Kim M et al. A critical role for p27kip1 gene dosage in a mouse model of prostate carcinogenesis. Proc Natl Acad SCi USA 2004; 101: 17204-17209.

39. O'Connor L, Strasser A, O'Reilly LA, Hausmann G, Adams JM, Cory S et al. Bim: a novel member of the Bcl-2 family that promotes apoptosis. EMBO J 1998; 17: 384-395.

40. Laramas M, Pasquier D, Filhol O, Ringeisen F, Descotes J-L, Cochet C. Nuclear localization of protein kinase CK2 catalytic subunit (CK2 $\alpha$ ) is associated with poor prognostic factors in human prostate cancer. Eur J Cancer 2007; 43: 928-934.

41. Gurrieri C, Capodieci P, Bernardi R, Scaglioni PP, Nafa K, Rush LJ et al. Loss of the tumor suppressor PML in human cancers of multiple histologic origins. J Natl Cancer Inst 2004; 96: 269-279.

42. Majumder PK, Sellers WR. Akt-regulated pathways in prostate cancer. Oncogene 2005; 24: $7465-7474$

43. Ruzzene M, Di Maira G, Tosoni K, Pinna LA. Assessment of CK2 constitutive activity in cancer cells. Methods Enzymol 2010; 484: 495-514.

44. Münstermann U, Fritz G, Seitz G, Lu YP, Schneider HR, Issinger OG. Casein kinase II is elevated in solid human tumours and rapidly proliferating non-neoplastic tissue. Eur $J$ Biochem 1990; 189: 251-257.

45. Slaton JW, Unger GM, Sloper DT, Davis AT, Ahmed K. Induction of apoptosis by antisense CK2 in human prostate cancer xenograft model. Mol Cancer Res 2004; 2 712-721.

46. Bernardi R, Papa A, Pandolfi PP. Regulation of apoptosis by PML and the PML-NBs. Oncogene 2008; 27: 6299-6312.

47. O'Neill AK, Niederst MJ, Newton AC. Suppression of survival signalling pathways by the phosphatase PHLPP. FEBS J 2012; 280: 572-583

48. Ghosh PM, Malik S, Bedolla R, Kreisberg Jl. Akt in prostate cancer: possible role in androgen-independence. Curr Drug Metab 2003; 4: 487-496.

49. Shukla S, Shukla M, MacLennan GT, Fu P, Gupta S. Deregulation of FOXO3A during prostate cancer progression. Int J Oncol 2009; 34: 1613-1620.

50. Li Y, Wang Z, Kong D, Murthy S, Dou QP, Sheng S et al. Regulation of FOXO3a/ $\beta$-Catenin/GSK-3 $\beta$ signaling by $3,3^{\prime}$-diindolylmethane contributes to inhibition of cell proliferation and induction of apoptosis in prostate cancer cells. J Biol Chem 2007; 282: 21542-21550.

51. Reagan-Shaw S, Ahmad N. The role of Forkhead-box Class O (FoxO) transcription factors in cancer: a target for the management of cancer. Toxicol Appl Pharmacol 2007; 22 : 360-368

52. Yang J-Y, Xia W, Hu MC. Ionizing radiation activates expression of FOXO3a, Fas ligand, Bim, and induces cell apoptosis. Int J Oncol 2006; 29: 643-648.

53. Choudhury KR, Yagle KevinJ, Swanson PaulE, Krohn KennethA, Rajendran JG. A robust automated measure of average antibody staining in immunohistochemistry images. J Histochem Cytochem 2010; 58: 95-107.

54. Ghosh MK, Sharma P, Harbor PC, Rahaman SO, Haque SJ. PI3K-AKT pathway negatively controls EGFR-dependent DNA-binding activity of Stat3 in glioblastoma multiforme cells. Oncogene 2005; 24: 7290-7300.

55. Pagano MA, Poletto G, Di Maira G, Cozza G, Ruzzene M, Sarno S et al. Tetrabromocinnamic acid (TBCA) and related compounds represent a new class of specific protein kinase CK2 inhibitors. Chembiochem 2007; 8: 129-139.

56. Ho SN, Hunt HD, Horton RM, Pullen JK, Pease LR. Site-directed mutagenesis by overlap extension using the polymerase chain reaction. Gene 1989; 77: 51-59.

57. Paul I, Ahmed SF, Bhowmik A, Deb S, Ghosh MK. The ubiquitin ligase CHIP regulates c-Myc stability and transcriptional activity. Oncogene 2012; e-pub ahead of print 30 April 2012; doi:10.1038/onc.2012.144.

(c) (i) () $)$ Cell Death and Disease is an open-access journal published by Nature Publishing Group. This work is licensed under a Creative Commons Attribution-NonCommercialNoDerivs 3.0 Unported License. To view a copy of this license, visit http://creativecommons.org/licenses/by-nc-nd/3.0/

\section{Supplementary Information accompanies this paper on Cell Death and Disease website (http://www.nature.com/cddis)}

